\title{
Five-year Experience of Extracorporeal Life Support in Emergency Physicians
}

\author{
Yong Soo Cho ${ }^{1}$, Kyoung Hwan Song' ${ }^{2}$, Byung Kook Lee ${ }^{1}$, Kyung Woon Jeung ${ }^{1}$, \\ Yong Hun Jung ${ }^{1}$, Dong Hun Lee ${ }^{1}$, and Sung Min Lee ${ }^{1}$
}

${ }^{1}$ Department of Emergency Medicine, Chonnam National University Hospital, Gwangju; ' 2 Department of Emergency Medicine, KS Hospital, Gwangju, Korea

Background: This study aimed to present our 5-year experience of extracorporeal cardiopulmonary resuscitation (ECPR) performed by emergency physicians.

Methods: We retrospectively analyzed 58 patients who underwent ECPR between January 2010 and December 2014. The primary parameter analyzed was survival to hospital discharge. The secondary parameters analyzed were neurologic outcome at hospital discharge, cannulation time, and ECPR-related complications.

Results: Thirty-one patients (53.4\%) were successfully weaned from extracorporeal membrane oxygenation, and 18 (31.0\%) survived to hospital discharge. Twelve patients (20.7\%) were discharged with good neurologic outcomes. The median cannulation time was $25.0 \mathrm{~min}$ (interquartile range 20.0-31.0 min). Nineteen patients $(32.8 \%)$ had ECPR-related complications, the most frequent being distal limb ischemia. Regarding the initial presentation, 52 patients (83.9\%) collapsed due to a cardiac etiology, and acute myocardial infarction $(33 / 62,53.2 \%)$ was the most common cause of cardiac arrest.

Conclusions: The survival to hospital discharge rate for cardiac arrest patients who underwent ECPR conducted by an emergency physician was within the acceptable limits. The cannulation time and complications following ECPR were comparable to those found in previous studies.

Key Words: cardiopulmonary resuscitation; extracorporeal membrane oxygenation; heart arrest; treatment outcome.

\section{Introduction}

Cardiac arrest is a leading cause of death, although there is a wide variation in incidence depending on the region [1]. Despite advances in cardiopulmonary resuscitation (CPR) techniques and treatment, many cardiac arrest victims do not respond to resuscitation, resulting in death. Extracoporeal life support (ECLS) is a device that temporarily maintains cardiac and pulmonary function during cardiopulmonary failure, allowing organ recovery time. Chen et al. [2] have suggested ECLS as a therapeutic option in refractory cardiac arrest. However, there is insufficient evidence to recommend its routine use for cardiac arrest, although the American Heart Association recommended ECLS when the "no flow" time was brief and the cause of cardiac arrest was potentially reversible [3].

Several studies have been performed on ECLS use in cases of out-of-hospital cardiac arrest (OHCA) [4-7]. Kagawa

\footnotetext{
Received on October 25, 2016 Revised on December 19, 2016 Accepted on February 9, 2017

Correspondence to: Byung Kook Lee, Department of Emergency Medicine, Chonnam National University Hospital, 42 Jebong-ro, Dong-gu, Gwangju 61469, Korea

Tel: +82-62-220-6809, Fax: +82-62-228-7417, E-mail: bbukkuk@hanmail.net
}

${ }^{\star}$ No potential conflict of interest relevant to this article was reported.

(c) This is an Open Access article distributed under the terms of the Creative Commons Attribution Non-Commercial License (http://creativecommons.org/ licenses/by-nc/4.0/) which permits unrestricted non-commercial use, distribution, and reproduction in any medium, provided the original work is properly cited. Copyright (c) 2017 The Korean Society of Critical Care Medicine 
et al. [8] reported that the difference in ECLS outcomes between in-hospital cardiac arrest (IHCA) and OHCA is associated with patient factors and the time delay in starting ECLS because there was no difference in outcomes after adjusting for these factors. To reduce the delay in treatment, rapid access to the patient is essential. ECLS performed by emergency physicians can provide such rapidity, but there is little research on the efficacy of this strategy. Therefore, we aim to describe our experiences with extracorporeal CPR (ECPR) performed by emergency physicians over a 5-year period.

\section{Materials and Methods}

\section{1) Design and setting}

This was a retrospective, observational, cohort study using medical records of patients treated with ECPR from January 2010 to December 2014. This study was approved by the Institutional Review Board of Chonnam National University Hospital (CNUH), a universityaffiliated, 1,005-bed, tertiary-care hospital in Gwangju, Korea. The facility contains an urban emergency department (ED) with approximately 45,000 annual visits. CNUH was designated for 24/7 emergency percutaneous coronary intervention as well as therapeutic hypothermia.

\section{2) Patient selection}

All patients who underwent ECPR performed by an emergency physician in the ED, intensive care unit, or cardiac catheterization room were included in this study. ECLS was performed if patients were younger than 75 years and experiencing either IHCA, defined as persistent cardiopulmonary arrest with a reversible cause despite advanced cardiac life support (ACLS) for 15 minutes, or OHCA, defined as sustained ventricular fibrillation (VF) cardiac arrest despite 30 minutes of resuscitation effort (including basic life support and ACLS) [9]. The exclusion criteria were as follows: (1) unwitnessed cardiac arrest, (2) major preexisting medical comorbidities, (3) aortic dissection, (4) aortic insufficiency, (5) recent cere- brovascular accident, and (6) traumatic cardiac arrest.

\section{3) CPR and ECLS management}

If spontaneous circulation did not return when ACLS was continued per the guidelines, the attending emergency physicians decided on the initiation of ECPR per the inclusion and exclusion criteria. While traditional resuscitation efforts continued, the emergency physician either cannulated the femoral artery and vein using a modified Seldinger technique after performing a percutaneous puncture or, less commonly, performed direct exposure of the femoral vessels followed by cannulation. Typically, a 16-Fr (artery) and 20- to 22-Fr (vein) cannula (Edwards Life Science, Irvine, CA, USA) were inserted. When cannulation was complete, bypass tubing was connected to the arterial and venous cannulas, and flow and oxygenation were optimized using a centrifugal pump and hollow-fiber oxygenator (Capiox, Terumo Corp., Tokyo, Japan), respectively. Once adequate flow through the ECLS circuit was achieved, CPR was stopped. At that point, 5,000 units of unfractionated heparin were administered to maintain an activated clotting time of approximately $180-220 \mathrm{~s}$ per patient. Chest radiography was performed after cannulation to verify adequate cannula placement. Percutaneous coronary angiogram and/ or intervention, insertion of an intra-aortic balloon pump, and target-temperature management were performed as needed. An anterograde reperfusion catheter for distal limb perfusion was inserted if distal limb ischemia was suspected. After ECLS initiation, the emergency physician titrated the oxygenation to achieve a partial oxygen pressure $\left(\mathrm{PaO}_{2}\right) \leq 150 \mathrm{mmHg}$, as determined by bloodgas tests of the arterial-tubing blood. The pump flow was initiated at $2.5 \mathrm{~L} / \mathrm{m}^{2}$, and a vasopressor (norepinephrine or dopamine) was used to maintain a mean blood pressure of at least $60 \mathrm{mmHg}$. ECLS weaning was based on echocardiographic and physiologic assessments. The weaning criteria (i.e., when the flow was reduced to 0.5 $\mathrm{L} / \mathrm{min}$ ) were (1) improvement of the ejection fraction on echocardiographic assessment, (2) mixed venous oxygen saturation $\geq 70 \%$, or (3) no deterioration of the base ex- 
cess on arterial blood gas analysis, which was conducted every 4-6 hours. We attempted to maintain the mixed venous oxygen saturation and base excess as close to the normal range as possible, and the final weaning decision was determined by echocardiography [10]. The decision to discontinue ECLS support was based on evidence of either multi-organ failure, overwhelming sepsis, or severe neurological injury.

\section{4) Data and statistical analysis}

A chart review was performed on cardiac arrest patients treated with ECLS by an emergency physician, and the relevant clinical data were abstracted from inpatient records. Basic clinical information, cause of arrest, treatment, and outcome data were retrieved and collected from the patients' medical charts.

An arrest is presumed to be of cardiac etiology unless it is known or likely to have been caused by trauma, submersion, drug overdose, asphyxia, exsanguination, or any other noncardiac cause as best determined by rescuers [11]. The cardiac etiology was divided into myocardial infarction, heart failure, primary VF, pulmonary thromboembolism, and myocarditis depending on clinical diagnosis.

The cannulation time was calculated from the initiation time to the end of cannulation. The primary parameter analyzed was survival to hospital discharge. The secondary parameters analyzed were neurologic outcome at hospital discharge, cannulation time, and ECLS-related complication. The neurologic outcome was assessed using the Glasgow-Pittsburgh Cerebral Performance Categories (CPC) at discharge, recorded as CPC 1 (good performance), CPC 2 (moderate disability), CPC 3 (severe disability), CPC 4 (vegetative state), and CPC 5 (brain death or death) [12]. A good neurologic outcome was defined as a CPC of 1 or 2.

Statistical analysis was performed using SPSS version 19.0 (SPSS Inc., Chicago, IL, USA). The continuous variables were expressed as the mean and standard deviation or the median and interquartile range (IQR) based on normality. The categorical variables are displayed as frequency distributions (n) and simple percentages (\%).
Non-normally distributed continuous variables were compared using the Mann-Whitney U test. Statistical significance was defined as $\mathrm{p}<0.05$.

\section{Results}

Between January 2010 and December 31, 2014, there

Table 1. Baseline characteristics of cardiac arrest patients $(n=62)$

\begin{tabular}{|c|c|}
\hline Variable & Values \\
\hline Age (years) & $57.1 \pm 15.9$ \\
\hline Male:Female & $46(74.2): 16(25.8)$ \\
\hline \multicolumn{2}{|l|}{ Arrest rhythm } \\
\hline Ventricular fibrillation & $26(41.9)$ \\
\hline Asystole & $11(17.7)$ \\
\hline Pulseless electrical activity & $10(16.1)$ \\
\hline Pulseless ventricular tachycardia & $4(6.5)$ \\
\hline Unknown & $11(17.7)$ \\
\hline \multicolumn{2}{|l|}{ Site of cardiac arrest } \\
\hline In hospital & $34(54.8)$ \\
\hline Out of hospital & $28(45.2)$ \\
\hline \multicolumn{2}{|l|}{ Cause of arrest } \\
\hline Cardiac & $52(83.9)$ \\
\hline Acute myocardial infraction & $33(53.2)$ \\
\hline Heart failure & $8(12.9)$ \\
\hline Primary ventricular fibrillation & $5(8.1)$ \\
\hline Pulmonary thromboembolism & $4(6.5)$ \\
\hline Myocarditis & $2(3.2)$ \\
\hline Drug & $7(11.3)$ \\
\hline Drowning & $1(1.6)$ \\
\hline Unknown & $2(3.2)$ \\
\hline CPR duration, median (25th to 75th IQR) (minute) & $42(26.0-61.0)$ \\
\hline ACLS duration, median (25th to 75th IQR) (minute) & $38.0(20.50-55.0)$ \\
\hline Therapeutic hypothermia & $49(79.0)$ \\
\hline \multicolumn{2}{|l|}{ Result of percutaneous coronary intervention } \\
\hline Not performed & $28(45.2)$ \\
\hline Stenosis & $25(40.3)$ \\
\hline No stenosis & $6(9.7)$ \\
\hline No stenosis with spasm & $3(4.8)$ \\
\hline
\end{tabular}

Values are presented as mean \pm standard deviation or $n(\%)$ unless otherwise indicated.

CPR: cardiopulmonary resuscitation; IQR: interquartile range; ACLS: advanced cardiac life support. 
were 62 ECLS team activations. The basic population characteristics are shown in Table 1. The youngest patient was 14 years old. All patients were cannulated via the femoral artery and femoral vein. Fifty-two patients $(83.9 \%)$ collapsed due to a cardiac etiology, which consisted of myocardial infarction, heart failure, primary VF, pulmonary thromboembolism, and myocarditis. The most common cardiac etiology was acute myocardial infarction in $33(63.5 \%)$ of the 52 cardiac patients. VF was the most common first monitored rhythm, found in 26 $(41.9 \%)$ of the 62 total patients.

The clinical outcomes of patients who underwent ECPR are shown in Table 2. Of the 62 patients who received ECLS, 18 (29\%) survived to hospital discharge. Cannulation failed in 4 patients; of the remaining 58 patients, $12(20.7 \%)$ had a good neurologic outcome at discharge (CPC of 1 or 2). Of the total 62 patients, 31 $(53.4 \%)$ were successfully weaned from ECLS. Of those who died after ECLS, persistent cardiac dysfunction (25/40) was the most common cause of death. However, 13 pa-

Table 2. Clinical outcomes of patients who underwent ECPR

\begin{tabular}{lc}
\hline Variable & \multicolumn{1}{c}{ Values } \\
\hline Primary outcome $(n=62)$ & $18(29.0)$ \\
$\quad$ Survival to discharge & \\
Secondary outcome $(n=58)$ & $25.0(20.0-31.0)$ \\
\hline Cannulation time, median (25th to 75th IQR) (minute) & $7.5(2.0-17.0)$ \\
\hline ICU stay, median (25th to 75th IQR) (day) & $10.0(2.0-30.5)$ \\
\hline Hospital stay, median (25th to 75th IQR) (day) & $3.0(2.0-5.0)$ \\
\hline ECLS duration, median (25th to 75th IQR) (day) & $31(53.4)$ \\
\hline Weaned off ECMO & \\
\hline Discharge CPC & $12(20.7)$ \\
\hline 1-2 & $46(79.3)$ \\
\hline 3-5 & $19(32.8)$ \\
\hline ECLS-related complication & $7(12.1)$ \\
\hline Distal limb ischemia & $5(8.6)$ \\
\hline Vascular injury & $4(6.9)$ \\
\hline Cannulation site bleeding or hematoma & $3(5.2)$ \\
\hline Others &
\end{tabular}

Values are presented as n (\%) unless otherwise indicated. ECPR: extracorporeal cardiopulmonary resuscitation; IQR: interquartile range; ICU: intensive care unit; ECLS: extracorporeal life support; ECMO: extracoporeal membrane oxygenation; CPC: cerebral performance category. tients died after weaning from ECLS, 5 due to sepsis.

The median cannulation time was 25.0 minutes in our study. There was no significant difference with regard to cannulation time between the survivor and non-survivor groups (25.0 $\mathrm{min}$ [IQR 20.0-30.0] vs. $21.0 \mathrm{~min}$ [IQR 18.8-36.3], $\mathrm{p}=0.624)$.

Among the 62 patients, 19 patients (32.8\%) experienced ECLS-related complications. The most common complication was distal limb ischemia. Of these patients, 3 were treated with anterograde reperfusion therapy. Of the 5 patients who demonstrated vascular injury, 2 had retroperitoneal hemorrhage, 1 developed a femoral arteriovenous fistula that was treated with radiologic intervention, 1 had a femoral artery laceration that was treated with surgical repair, and 1 developed a femoral artery pseudoaneurysm. Four patients experienced cannulation site bleeding or hematoma.

\section{Discussion}

The reported rates of survival to discharge after ECPR vary from 27.0 to $34.1 \%$ [13-15]. According to an ECLS organization registry report in 2012, the overall rate of survival to discharge for adult ECPR patients is $27.0 \%$ [13]. Chen et al. [14] and Haneya et al. [15] reported survival to hospital discharge rates of $32.0 \%$ and $34.1 \%$, respectively, after ECPR for IHCA. The survival rate of $29 \%$ found in this study was somewhat lower than that found in previous studies. However, considering the inclusion of OHCA patients in this study, the survival to hospital discharge could be accepted as comparable with those of previous studies.

Surgical vascular access has been traditionally performed for cannulation for ECLS. However, a previous report showed the success of a percutaneous technique in ECLS [16]. Another report demonstrated femoral cannulation for ECLS support to be useful when conditions are not optimal for performing femoral vessel cutdown [17]. Percutaneous cannulation has several advantages over surgical cutdown. It can reduce the risk of bleeding, has 
a shorter operation time, and reduces infection risk. For these reasons, the percutaneous technique is considered a standard cannulation method in ECLS. Additionally, this method can be performed by either a surgeon or a nonsurgeon. Chen et al. [18] reported that a surgeon typically requires less than 30 minutes to set up the ECLS using a modified Seldinger technique. One article reported the mean cannulation time to be approximately 30 minutes [19], but there is insufficient research data about cannulation times in ECLS procedures performed by emergency physicians. Despite the difficulty of performing cannulation during CPR, the cannulation time in the present study was similar to that in previous studies. Therefore, cannulation time should not be considered an obstacle to ECLS performed by an emergency physician.

During ECLS, several ECLS-related complications can occur, such as leg ischemia, bleeding, and vessel injury. The reported rates of ECLS-related complications are variable [15,20-22]. Haneya et al. [15] reported that 33\% of all patients had ECLS-related complications. Similarly, in our study population, 19 patients $(32.8 \%)$ showed ECLS-related complications. Aziz et al. [20] reported a $17.8 \%$ vascular complication rate. Among these, acute ischemia of the lower extremities was the most common complication, accounting for $44.4 \%$ of vascular complications [20]. Similarly, in our study, distal leg ischemia was the most common complication. To prevent this complication, it is necessary to consider prompt prophylactic insertion of an anterograde reperfusion catheter into the femoral artery [23].

Another common complication of ECLS is bleeding. Kurusz and Zwischenberger [21] reported cannulationrelated bleeding rates ranging from $4 \%$ to $14 \%$. Anticoagulation is necessary to prevent coagulation associated with either the catheter or the ECLS circuit. However, this may lead to a hemorrhagic complication. Furthermore, multiple vessel punctures during cannulation, decreased platelet function, and thrombocytopenia may induce bleeding complications. In this study, 4 patients showed cannulation site bleeding or hematoma.

In our study, 5 patients (8\%) experienced vascular inju- ry, 2 of whom required surgical treatment or intervention. Conrad et al. [24] reported that 2 of 100 patients with severe respiratory and/or cardiac failure had failed cannulation due to vascular injury. Schwarz et al. [22] reported that cannulation-related vascular injury was found in $8 \%$ of cardiogenic shock patients and in 19\% of cardiac arrest patients. Recently published studies that included only ECPR reported 5.5 to $13 \%$ prevalence rates of cannulation-related vascular injury $[25,26]$. Therefore, cardiac arrest is thought to affect the incidence of vascular injury. It is difficult to perform the cannulations needed for ECLS during CPR for several possible reasons. First, it is hard to identify the femoral vessels because cardiac arrest patients have no pulse. Second, chest compression can interfere with the puncture of vessels and insertion of the cannula. More effort is required to reduce the incidence of cannulation-related vascular injury, and the sono-guided puncture technique is recommended as part of this goal [24].

It is critical to reduce the initiation of extracoporeal membrane oxygenation (ECMO) time after collapse in cardiac arrest. The CPR mechanical, hypothermia, ECMO, emergency, and reperfusion trial reported that patients who survived cardiac arrest had a significantly shorter median time of collapse to initiation of ECMO compared with the non-survivors [27]. Emergency physicians encounter critically ill patients on the frontline. Implementation of the appropriate treatment in these critical moments could save a patient's life. A recent study demonstrated that ECLS can be used a rescue procdure in adult OHCA or cardaic arrest patients in the ED who are not responsive to conventional CPR [28]. Another reported that emergency physicians can successfully initiate ECLS without compromising the optimal traditional resuscitative techniques [29].

In our study, the main cause of death in patients who died after ECLS was persistent cardiac dysfunction (25/40). In those patients who regain consciousness, use of a ventricular assist device or heart transplantation should be considered. Unfortunately, this surgery is not generally performed in our hospital. 
Our study had several limitations, the main one being that it was a retrospective, observational study. Several of the medical documents were either incompletely or illegibly recorded. Consequently, some patient data could not be retrieved. Additionally, this retrospective design had no control group, possibly resulting in selection bias. Another limitation is that this study was performed in a single center; accordingly, the results cannot be generalized across centers. Finally, the number of patients is relatively small, making statistical analysis difficult.

The survival to hospital discharge rate, cannulation time, and occurrence of complications following ECPR performed by emergency physicians were comparable with those found in previous studies. Our experiences suggest that it is feasible for emergency physicians to implement ECPR for cardiac arrest. More studies are required to evaluate the cost-effectivenss, patients selection, and prognostication of ECPR.

\section{Acknowledgements}

The study was performed in accordance with the ethical standards of the Declaration of Helsinki and was approved by the institutional review board of CNUH.

\section{ORCID}

Yong Soo Cho

Byung Kook Lee

http://orcid.org/0000-0001-8306-2298

Kyung Woon Jeung

http://orcid.org/0000-0003-3571-9448

Dong Hun Lee

http://orcid.org/0000-0002-3478-6967

http://orcid.org/0000-0003-3612-3443

\section{References}

1. Lloyd-Jones D, Adams RJ, Brown TM, Carnethon M, Dai S, De Simone G, et al. Heart disease and stroke statistics--2010 update: a report from the American Heart Association. Circulation 2010; 121: e46-215.

2. Chen YS, Lin JW, Yu HY, Ko WJ, Jerng JS, Chang WT, et al. Cardiopulmonary resuscitation with as- sisted extracorporeal life-support versus conventional cardiopulmonary resuscitation in adults with in-hospital cardiac arrest: an observational study and propensity analysis. Lancet 2008; 372: 554-61.

3. Cave DM, Gazmuri RJ, Otto CW, Nadkarni VM, Cheng A, Brooks SC, et al. Part 7: CPR techniques and devices: 2010 American Heart Association guidelines for cardiopulmonary resuscitation and emergency cardiovascular care. Circulation 2010; 122(18 Suppl 3): S720-8.

4. Morimura N, Sakamoto T, Nagao K, Asai Y, Yokota H, Tahara Y, et al. Extracorporeal cardiopulmonary resuscitation for out-of-hospital cardiac arrest: a review of the Japanese literature. Resuscitation 2011; 82: 10-4.

5. Maekawa K, Tanno K, Hase M, Mori K, Asai Y. Extracorporeal cardiopulmonary resuscitation for patients with out-of-hospital cardiac arrest of cardiac origin: a propensity-matched study and predictor analysis. Crit Care Med 2013; 41: 1186-96.

6. Lamhaut L, Jouffroy R, Soldan M, Phillipe P, Deluze T, Jaffry M, et al. Safety and feasibility of prehospital extra corporeal life support implementation by non-surgeons for out-of-hospital refractory cardiac arrest. Resuscitation 2013; 84: 1525-9.

7. Le Guen M, Nicolas-Robin A, Carreira S, Raux M, Leprince P, Riou B, et al. Extracorporeal life support following out-of-hospital refractory cardiac arrest. Crit Care 2011; 15: R29.

8. Kagawa E, Inoue I, Kawagoe T, Ishihara M, Shimatani Y, Kurisu S, et al. Assessment of outcomes and differences between in- and out-of-hospital cardiac arrest patients treated with cardiopulmonary resuscitation using extracorporeal life support. Resuscitation 2010; 81: 968-73.

9. Thiagarajan RR, Brogan TV, Scheurer MA, Laussen PC, Rycus PT, Bratton SL. Extracorporeal membrane oxygenation to support cardiopulmonary resuscitation in adults. Ann Thorac Surg 2009; 87: 778-85.

10. Massetti M, Tasle M, Le Page O, Deredec R, Babatasi G, Buklas D, et al. Back from irreversibility: ex- 
tracorporeal life support for prolonged cardiac arrest. Ann Thorac Surg 2005; 79: 178-83.

11. Jacobs I, Nadkarni V, Bahr J, Berg RA, Billi JE, Bossaert L, et al. Cardiac arrest and cardiopulmonary resuscitation outcome reports: update and simplification of the Utstein templates for resuscitation registries. A statement for healthcare professionals from a task force of the international liaison committee on resuscitation (American Heart Association, European Resuscitation Council, Australian Resuscitation Council, New Zealand Resuscitation Council, Heart and Stroke Foundation of Canada, InterAmerican Heart Foundation, Resuscitation Council of Southern Africa). Resuscitation 2004; 63: 233-49.

12. Booth CM, Boone RH, Tomlinson G, Detsky AS. Is this patient dead, vegetative, or severely neurologically impaired? Assessing outcome for comatose survivors of cardiac arrest. JAMA 2004; 291: 870-9.

13. Paden ML, Conrad SA, Rycus PT, Thiagarajan RR; ELSO Registry. Extracorporeal life support organization registry report 2012. ASAIO J 2013; 59: 20210.

14. Chen YS, Chao A, Yu HY, Ko WJ, Wu IH, Chen RJ, et al. Analysis and results of prolonged resuscitation in cardiac arrest patients rescued by extracorporeal membrane oxygenation. J Am Coll Cardiol 2003; 41: 197-203.

15. Haneya A, Philipp A, Diez C, Schopka S, Bein T, Zimmermann M, et al. A 5-year experience with cardiopulmonary resuscitation using extracorporeal life support in non-postcardiotomy patients with cardiac arrest. Resuscitation 2012; 83: 1331-7.

16. Pranikoff T, Hirschl RB, Remenapp R, Swaniker F, Bartlett RH. Venovenous extracorporeal life support via percutaneous cannulation in 94 patients. Chest 1999; 115: 818-22.

17. Roussel A, Al-Attar N, Alkhoder S, Radu C, Raffoul $\mathrm{R}$, Alshammari $\mathrm{M}$, et al. Outcomes of percutaneous femoral cannulation for venoarterial extracorporeal membrane oxygenation support. Eur Heart J Acute Cardiovasc Care 2012; 1: 111-4.
18. Chen YS, Ko WJ, Lin FY. Insertion of percutaneous ECMO cannula. Am J Emerg Med 2000; 18: 184-5.

19. Migliari M, Marcolin R, Avalli L, Bombino M. Percutaneous cannulation: indication, technique, and complications. In: Ecmo-Extracorporeal Life Support in Adults. Editor by Sangalli F, Patroniti N, Pesenti A. New York: Springer; 2014. pp 44.

20. Aziz F, Brehm CE, El-Banyosy A, Han DC, Atnip RG, Reed AB. Arterial complications in patients undergoing extracorporeal membrane oxygenation via femoral cannulation. Ann Vasc Surg 2014; 28: 17883.

21. Kurusz M, Zwischenberger JB. Percutaneous cardiopulmonary bypass for cardiac emergencies. Perfusion 2002; 17: 269-77.

22. Schwarz B, Mair P, Margreiter J, Pomaroli A, Hoermann $\mathrm{C}$, Bonatti J, et al. Experience with percutaneous venoarterial cardiopulmonary bypass for emergency circulatory support. Crit Care Med 2003; 31: 758-64.

23. Foley PJ, Morris RJ, Woo EY, Acker MA, Wang GJ, Fairman RM, et al. Limb ischemia during femoral cannulation for cardiopulmonary support. J Vasc Surg 2010; 52: 850-3.

24. Conrad SA, Grier LR, Scott LK, Green R, Jordan M. Percutaneous cannulation for extracorporeal membrane oxygenation by intensivists: a retrospective single-institution case series. Crit Care Med 2015; 43: 1010-5.

25. Lee JJ, Han SJ, Kim HS, Hong KS, Choi HH, Park KT, et al. Out-of-hospital cardiac arrest patients treated with cardiopulmonary resuscitation using extracorporeal membrane oxygenation: focus on survival rate and neurologic outcome. Scand J Trauma Resus Emerg Med 2016; 24: 74.

26. Lee DS, Chung CR, Jeon K, Park CM, Suh GY, Song YB, et al. Survival after extracorporeal cardiopulmonary resuscitation on weekends in comparison with weekdays. Ann Thorac Surg 2016; 101: 133-40.

27. Stub D, Bernard S, Pellegrino V, Smith K, Walker T, Sheldrake J, et al. Refractory cardiac arrest treated 
with mechanical CPR, hypothermia, ECMO and early reperfusion (the CHEER trial). Resuscitation 2015; 86: 88-94.

28. Johnson NJ, Acker M, Hsu CH, Desai N, Vallabhajosyula P, Lazar S, et al. Extracorporeal life support as rescue strategy for out-of-hospital and emergency department cardiac arrest. Resuscitation 2014; 85: 1527-32.

29. Bellezzo JM, Shinar Z, Davis DP, Jaski BE, Chillcott S, Stahovich M, et al. Emergency physician-initiated extracorporeal cardiopulmonary resuscitation. Resuscitation 2012; 83: 966-70. 